\title{
The spread of weeds into sensitive areas by seeds in horse faeces
}

\author{
E van Dyk ${ }^{a}$ and S Neser
}

\begin{abstract}
The possiblespread by horsefaeces of plants that may become weeds in sensitiveareas was investigated. It was found that the period $24-48$ hours after ingestion of seeds included in rations was the retention time for seeds passing through the digestive system of the horse. The ability of seeds to germinate was not influenced by exposure to digestive fluids or seawater. A feeding regime of compound feeds is suggested.

Key words: faeces, horses, weeds.

Van DykE, N eser SThe spread of weeds into sensitive areas by seeds in horse faeces. Journal of the South African Veterinary Association (2000) 71(3): 173-174 (En.). Department of Veterinary Production and Ethology, Faculty of Veterinary Science, Private Bag X04, Onderstepoort, 0110 South Africa.
\end{abstract}

\section{INTRODUCTION}

Permission is often requested to allow horse-riding and trekking in nature re serves, on beachesand in other potentially sensitive areas for recreational purposes. Oneof theconcerns raised isthe potential spread of weeds via the faeces. Eragrostis curvula (love grass), E. teff (teff), M edigaco sativa (lucerne) and Avenia sativa (oats) are normal components of horse rations. Seeds may occur either in the concentrate or in the roughage fed. If the seeds pass through the digestive system and remain able to germinate, they could grow in areas where they do not occur naturally and are unwanted. Once established in sensitive areas they could become a problem, and would be regarded as weeds.

The objective of this study was to establish the retention time for seeds passing through the digestive tract and theability of such seeds to germinate after exposure to digestive fluids. The possible effect of seawater on their ability to germinate was also investigated, as riding on beaches often takes place and droppings may be affected by high tide.

A feeding regime is proposed to eliminate the problem and prospective recreational riding operators in sensitive areas are advised of safe procedures to follow.

\section{MATERIALS AND METHODS}

Six horses of varied breed, age and sex were used. They were fed a diet of $50 \%$ teff : $50 \%$ lucerne roughage and a concentrate mix of yellow maize meal and

${ }^{a}$ Department of Veterinary Production and Ethology, University of Pretoria, Private Bag X04, Onderstepoort, 0110 South Africa.

${ }^{\text {b} W e e d s ~ R e s e a r c h ~ D i v i s i o n, ~ P r i v a t e ~ B a g ~ X 134, ~ P r e t o r i a ~}$ 0001 South Africa.

Received: May 2000. Accepted: August 2000. wheat bran. The experiment was repeated once. In the 1st trial thehay used in the ration was harvested at an early stage of growth and no seed was present in thehay. Collections of faecesweremade $18 \mathrm{~h}, 30 \mathrm{~h}$ and $42 \mathrm{~h}$ after the ration had been supplied. In the $2 \mathrm{nd}$ trial, the teff hay fed as part of the ration was of a different quality. It had been cut after the boot stage and many seeds were visible. In both trials each horse was fed $100 \mathrm{~g}$ teff seed, $100 \mathrm{~g}$ lucerne seed and $100 \mathrm{~g}$ oats.

In the 2nd trial, the faeces were collected 12 times at 6 - $h$ intervals until $72 \mathrm{~h}$ after the seeds had been consumed. The horses were confined in a crush and the faeces were collected per rectum. A gloved hand, with a disposable armlength examination glove (yellow super touch) lubricated with water, was inserted into the rectum. About 3-4 faecal balls were collected and enclosed in the inverted disposable glove. The gloves served as transportation containers for every sample collected. Contamination with seeds from spilt hay that had not passed through the digestive system was thus impossible.

The samples were processed at the ARC - Plant Protection Research Institute at Rietondale. A sub-sample of each was spread out evenly to a thickness of about $20 \mathrm{~mm}$ on the surface of river-sand- and peat-filled plant pots, compressed lightly, and kept under natural daylight conditions in a water-cooled greenhouse. Temperatures were regulated to a minimum of $20^{\circ} \mathrm{C}$ during the night and $25-30^{\circ} \mathrm{C}$ during the day. The pots received overhead irrigation from borehole water during the day.

One plant pot with river sand and no faeces, 1 plant pot with peat and no faeces, and 1 pot with river sand and a mixture of M. sativa, A. sativa, E teff, and a pot with peat and a mixture of M. sativa, Triticum $\mathrm{sp}$. and E. teff, served as the controls. There were 3 replicates, i.e. 2 pots per sample ( 1 sand, 1 peat) and 1 pot per sample where the faeces were submerged in reconstituted seawater (see below) before spreading them out on a sand-filled plant pot. In the 2nd trial, only sand was used, and 2 pots per sample were spread out, because no difference had been observed between germination on peat and on sand in the 1st trial.

Synthetic sea salt was used to simulate seawater. Instant 0 cean salt (Aqua Pet Products, Benoni) was mixed with distilled water. While mixing, the water was aerated until it reached oxygen/carbon dioxide equilibrium. Specific gravity was adjusted to $1.020-1.023$ at $23^{\circ} \mathrm{C}$.

The faeces were submerged for $8 \mathrm{~h}$ to simulatehigh tide, and then spread out in the sand-filled pots, and treated as the other samples.

The number of seedlings per faecal sample in each plant pot was recorded.

\section{RESULTS}

In the collected faeces the M. sativa seeds were swollen, i.e. had already imbibed fluids. The seeds, red when dry, were white as the testa had ruptured and the cotyledons were exposed. The A. sativa seeds were also distinctly swollen. E. teff seeds are very small and no increase in size was discernible microscopically.

In the pots with peat, or sand, to which seeds in the original ration had been added, closeto $100 \%$ germination occurred in the 3 species. No germination took place in peat- or sand-filled pots without faeces.

In the 1st trial, seeds were present in samples taken at $18 \mathrm{~h}, 30 \mathrm{~h}$ and $42 \mathrm{~h}$ (Fig. 1). In the 2nd trial, in which samples were collected 6-72 h after ingestion, teff seedlings germinated in all samples, with a peak between $30 \mathrm{~h}$ and $48 \mathrm{~h}$. Lucerne seedlings germinated between $24 \mathrm{~h}$ and $48 \mathrm{~h}$, and oats seedlings germinated at $30 \mathrm{~h}$ and $36 \mathrm{~h}$ (Fig. 2). These results demonstrate that the seeds retained their viability after having passed through the digestive system. 


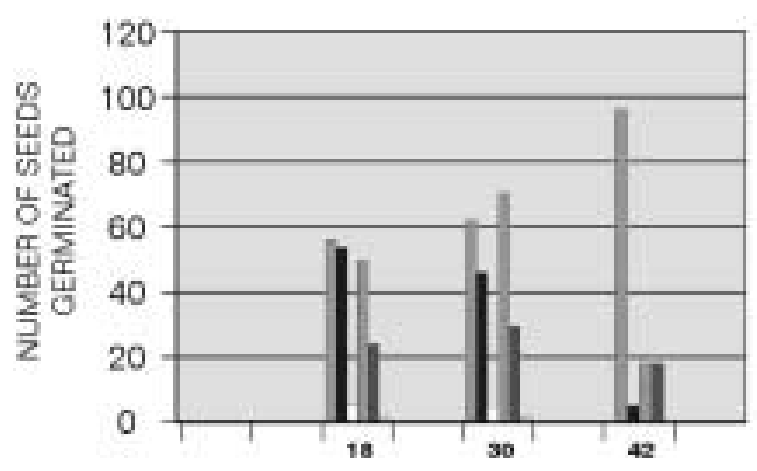

HOUAS AFTEA INGESTION OF SEEDS

Fig. 1: Number of germinated seeds in faecal samples taken at 18, 30 and $42 \mathrm{~h}$ after ingestion.

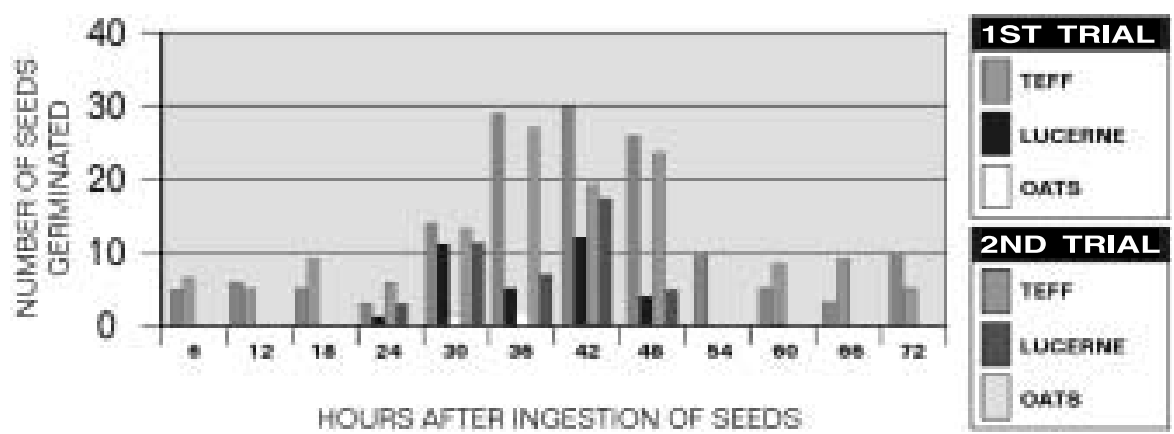

Fig. 2: Number of germinated seeds in faecal samples taken at 6-hourly intervals after ingestion.

Faeces sampled at 6-72 $\mathrm{h}$ and submerged for $8 \mathrm{~h}$ in reconstituted seawater also yielded teff and lucerne seeds that germinated in samples taken at 24-48 h, but neither earlier nor later (Fig. 3).

\section{DISCUSSION}

The recorded retention time for food passing through the digestive system of the horse is up to $51 \mathrm{~h}$ : most digesta reach the caecum $3 \mathrm{~h}$ after a meal and remain in thelarge intestine for $48 \mathrm{~h}^{6} . \operatorname{In}$ the present study, theseedswereexcreted between 18 and $48 \mathrm{~h}$ (1st trial) and 24-48 $\mathrm{h}$ in the expanded 2 nd trial after ingestion as part of a normal diet. The faster passage of seeds in the faeces in the 1st trial may be explained by the better quality of hay (cut well before the boot stage) and the pres-

ence of green pasture at the time. In the 2nd trial, with poorer quality hay (cut when the seeds were nearly mature), some teff seeds from each faeces sample germinated (Fig. 2). These seeds had obviously been present in the rations. Curiously, when the faeces were submerged in the reconstituted seawater, no teff or lucerne seeds germinated in the samples taken before $24 \mathrm{~h}$ and after $54 \mathrm{~h}$. This may have been due to the action of the salt solution on the seeds that passed through the digestive system in either a short period or after taking up water during the 24-48 h spent in the gut.

The critical time for the dispersal of seeds via the faeces was therefore 18-48 $\mathrm{h}$ after ingestion of rations containing seeds, when caution should be exercised
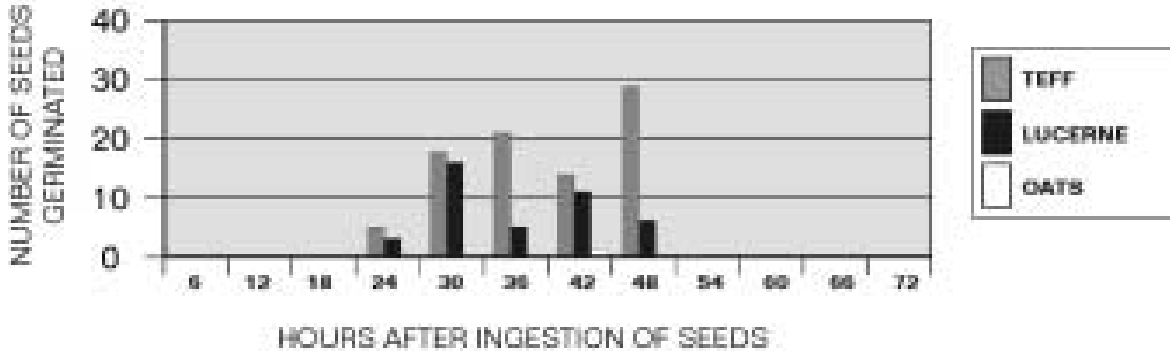

Fig. 3: Number of germinated seeds in faecal samples taken at 6-72 $\mathrm{h}$ after ingestion and then submerged for $\mathbf{8} \mathrm{h}$ in reconstituted seawater. when taking horses into sensitive areas. Immersion of seeds in seawater did not affect the ability of seeds, that had passed through the gut of horses, to germinate.

The ability to germinate after having been exposed to digestive fluids seemed to be enhanced, since swelling of seeds and rupturing of the testa was observed. This corresponds with the findings of Lamprey, ${ }^{5}$ who showed that the action of digestive fluids in the mammalian gut results in a shorter germination time. Red deer $^{4}$, rhino ${ }^{1}$, other herbivorous animals ${ }^{3}$, birds $s^{5}$ and elephants $s^{2,7}$ are all able to disperse seeds via their faeces. The seeds are also deposited in a perfect seedbed, aerated and rich in humus and nitrogenous matter.

Theflooding of faeces with salt water did not affect the ability of seeds to germinate. Faeces dropped on the beach are therefore still a potential source of unwanted plants.

In a feeding regime, hay that has been cut at a very early stage, so that no seeds are present, should preferably be used. Otherwise, compound feeds in the form of complete cubes can be fed alone and replaceall the hay and concentratesin the horse's ration. Such cubes are, however, high in fibre and low in energy, and the diet of horses should be supplemented, depending on their workload. Concentrate cubes that provide a balanced source of nutrients could be fed together with the complete cubes. The cereal grains in these cubes have been processed and have therefore lost their ability to germinate. Well-planned, carefully-timed feeding regimes, taking into consideration the 'safe' intervals suggested here, should be implemented.

\section{REFERENCES}

1. Dinerstein E 1991 Seed dispersal by greater one-horned rhinoceros (Rhinoceros unicornis) and the flora of R hinoceros latrines. $M$ ammalia 55: 355-362

2. Koen J H 1983Seed dispersal by theKnysna elephants. South African Journal of Forestry 124: 56-58

3. Malo J E, Suàrez F 1995 Herbivorous mammals as seed dispersers in a Mediterranean dehesa. 0 ecologia 104: 246-255

4. Malo J E, Suàrez $F$ 1997 The dispersal of a dry-fruited shrub by red deer in a Mediterranean ecosystem. Ecography 21: 204-211

5. Lamprey H F 1967 Notes on the dispersal and germination of someseedsthrough the agency of mammals and birds. East African Journal 179: 180

6. Pilliner S $1996 \mathrm{H}$ orse nutrition and feeding. Blackwell Science, Oxford

7. Yomoto T, Maruhashi T 1995 Seed-dispersal by elephants in a tropical rain forest in Kahusi-Biega National Park, Zaire. Biotropica 27: 526-529 